\title{
Relationship between female fertility and production traits in Canadian Holsteins
}

\author{
A. Sewalem, ${ }^{*} \dagger^{1}$ G. J. Kistemaker, $\dagger$ and F. Miglior ${ }^{*} \dagger$ \\ *Guelph Food Research Centre, Agriculture and Agri-Food Canada, Guelph, ON, Canada, N1G 5C9 \\ †Canadian Dairy Network, Guelph, ON, Canada, N1K 1E5
}

\begin{abstract}
The objectives of this study were a) to estimate the genetic correlation between milk production and some female fertility traits such as 56-d nonreturn rate in cows (NRRC), calving to first service (CTFS), and first service to conception (FSTC); b) to assess the influence of including milk production as a correlated trait on the genetic evaluation of these traits in Canadian Holsteins; and c) to determine if using heifer nonreturn rate (NRRH) had a similar effect as using milk production on cow NRRC evaluation. The data included fertility and production records of first-parity Holstein cows. Genetic parameters were estimated using uni- and bivariate analyses in which milk production at around 90 DIM (TD90M) was included as a correlated trait to NRRC, CTFS, and FTSC. A bivariate analysis was also carried out in which NRRH was included as a correlated trait to NRRC. The models were compared by genetic trend (NRRC, CTFS, and FSTC) and cross-validation and predictability (NRRC). The heritability estimates for NRRC from the uni- and bivariate analyses were 0.017 and 0.020 , respectively. The corresponding figures for CTFS were 0.07 and 0.08 and for FSTC were 0.049 and 0.05 . The genetic trends for NRRC of the 2 models $(\mathrm{NRRC}+\mathrm{TD} 90 \mathrm{M}$ and NRRC+NRRH) gave very similar results. However, when milk production was included in the genetic evaluation of CTFS and FSTC, the genetic trends of the 2 fertility traits were higher compared with the univariate analysis. In NRRC evaluation by cross-validation and predictability, the bivariate analyses were more consistent and gave a better predictability than the univariate analysis. However, there was no major difference between the 2 models. Consequently, it might be worth including milk production or heifer fertility as correlated traits in the genetic evaluation of female fertility traits.
\end{abstract}

Key words: fertility, accounting for selection, multiple-trait analysis

Received November 16, 2009.

Accepted May 20, 2010.

${ }^{1}$ Corresponding author: Asheber.Sewalem@agr.gc.ca

\section{INTRODUCTION}

Reproductive performance is one of the major factors that influences the overall efficiency and profitability of the dairy industry. Nonetheless, for many years, dairy cattle research breeding programs were mainly oriented toward yield traits. This was true for most countries with the exception of Scandinavian countries, whose selection indices also included health and reproduction, and North American countries, whose selection indices included conformation together with production (Miglior et al., 2005). Functional traits such as fertility, longevity, and health traits have a considerable effect on the overall efficiency of dairy cattle production. Consequently, these traits are of increasing interest to producers to improve herd profitability. Even so, various reports indicate that breeding for increased production in dairy cattle has negative side effects on health and fertility traits because of antagonistic genetic correlations between production and reproduction traits (Veerkamp et al., 2001; Kadarmideen et al., 2003; Pryce et al., 2004; Melendez and Pinedo, 2007) and production and health traits (Kadarmideen et al., 2000).

Generally, selection for increased production reduces reproductive efficiency (Grosshans et al., 1997; Dematawewa and Berger, 1998; Castillo-Juarez et al., 2000) and increases susceptibility to some diseases and the risk of culling due to diseases and other abnormalities (Simianer et al., 1991; Dematawewa and Berger, 1998; Sewalem et al., 2006). Inadequate herd reproductive performance (manifested in prolonged calving intervals), increased forced culling, or both, can result in less milk and fewer calves per cow per year, less volunteer culling and therefore increased replacement cost, and ultimately, lower net returns (Wall et al., 2003; Gonzalez-Recio et al., 2004, 2006). High-producing cows tend to be less fertile, and this prolongs the length of calving interval, as well as the rate of involuntary culling. In addition, less fertile cows have decreased longevity (Sewalem et al., 2008) and their lifetime production can be less than that of cows with adequate fertility (González-Recio et al., 2004). Hence, a balance between production and functional 
traits must be pursued, and proper economic weights must be applied to every trait.

In a review of national selection indices in several countries, Miglior et al. (2005) indicated that the importance of reproduction traits in dairy cattle breeding programs has increased dramatically in the last 10 yr. Several countries have included fertility traits in their national breeding objectives. However, others may argue that direct selection for fertility traits may be inefficient because these traits have low heritability (Kadarmideen et al., 2003; Jamrozik et al., 2005) resulting in low accuracy of EBV, especially for cows and young bulls. Hence, selection decisions for these traits often involve a great deal of uncertainty.

Intensive selection for milk production has been carried out for a long time and hence genetic evaluation of fertility traits might be biased by not accounting for the early selection decisions that were made (Kadarmideen et al., 2003). Walter and Mao (1985) reported that selection bias in genetic parameter estimates of traits undergoing sequential selection can be reduced if these traits are analyzed simultaneously with traits that did not undergo selection. Pollak and Quaas (1981), using a simulation study, demonstrated that a single trait evaluation was biased by selection and the bias was removed by including records upon which the selection decision was made. Kadarmideen et al. (2003) recommended a joint evaluation of fertility traits and milk yield using a multiple trait approach. However, they did not test a joint evaluation of heifer and cow fertility traits. In Canada, Canadian Dairy Network (CDN) runs the official evaluation for reproduction using a multiple-trait animal model, which includes heifer and cow fertility and calving traits (Van Doormaal et al., 2007).

The objectives of this study were a) to estimate the genetic correlation between milk production and some female fertility traits; b) to assess the influence of including milk production as a correlated trait on the genetic evaluation of cow fertility traits; and c) to determine if using heifer 56-d nonreturn rate had a similar effect as using milk production on cow 56-d nonreturn rate evaluation.

\section{MATERIALS AND METHODS}

Data were obtained from lactation and reproduction records extracted for genetic evaluation of the Holstein breed with first calving occurring between 1997 and 2007. Traits studied were 56-d nonreturn rate in heifers (NRRH) and in cows (NRRC), days from calving to first service (CTFS), days from first service to conception (FSTC), and test-day milk yield closest to 90 DIM (TD90M), which is the average interval from calving to first service in first-lactation Holstein cows.
Nonreturn rate was defined as a cow or heifer that did not return in heat within $56 \mathrm{~d}$ of first insemination and was recorded as 0 (unsuccessful) or 1 (successful). For FTSC, a recorded subsequent calving was required. The data included records of first-parity cows with the exception of NRRH, which only included data from virgin heifers. Genetic parameters were estimated using univariate and bivariate analyses in which milk production (TD90M) was included as a correlated trait for all 3 female fertility traits. A bivariate analysis was also carried out in which NRRH was included as a correlated trait in evaluation of NRRC.

The traits were modeled using the following equations:

$$
\begin{gathered}
\text { NRRC }=\text { RYS }+ \text { HY }+ \text { RYSH }+ \text { AcMf } \\
+\mathrm{SSY}+\mathrm{TID}+\mathrm{A}+\mathrm{E}, \\
\mathrm{NRRH}=\mathrm{RYS}+\mathrm{HY}+\mathrm{RYSH}+\mathrm{Mf}+\mathrm{SSY} \\
+\mathrm{TID}+\mathrm{A}+\mathrm{E}, \\
\mathrm{FSTC}=\mathrm{RYS}+\mathrm{HY}+\mathrm{RYSH}+\mathrm{AcMc}+\mathrm{A}+\mathrm{E}, \\
\mathrm{CTFS}=\mathrm{RYS}+\mathrm{HY}+\mathrm{RYSH}+\mathrm{AcMc}+\mathrm{A}+\mathrm{E}, \\
\mathrm{TD} 90 \mathrm{M}=\mathrm{RYS}+\mathrm{HY}+\mathrm{RYSH}+\mathrm{AcMc}+\mathrm{A}+\mathrm{E},
\end{gathered}
$$

where RYS was a fixed effect of region (5 regions) by year of birth by season of birth (4 seasons: January to March, April to June, July to September, and October to December); HY was a fixed effect of herd by year of birth; RYSH was a random effect of region by herd by year by season of birth; AcMf was a fixed effect of age at calving by month of first insemination; Mf was a fixed effect of month of first insemination; AcMc was a fixed effect of age at calving by month of calving; SSY was a random effect of service sire by year of insemination; TID was a random effect of AI technician; A was a random animal additive genetic effect; and $\mathrm{E}$ was a random error term.

In matrix form, the multiple-trait model can be described as

$$
\mathbf{y}=\mathbf{X b}+\mathbf{Z}_{1} \mathbf{r}+\mathbf{Z}_{2} \mathbf{s}+\mathbf{Z}_{3} \mathbf{t}+\mathbf{Z}_{4} \mathbf{a}+\mathbf{e},
$$

where $\mathbf{y}$ is a vector of observations, $\mathbf{b}$ is a vector of all fixed effects, $\mathbf{r}$ is a vector of HRYS effects, $\mathbf{s}$ is a vector of service sire effects, $\mathbf{t}$ is a vector of AI technician (TID) effects, $\mathbf{a}$ is a vector of animal additive genetic effects (A), $\mathbf{e}$ is a vector of residuals, and $\mathbf{X}$ and $\mathbf{Z}_{\mathrm{i}}(\mathrm{i}=$ $1,4)$ are respective incidence matrices. 
The expectations and assumed variances are $\mathrm{E}(\mathrm{y})=$ $\mathrm{Xb} ; \mathrm{E}(\mathrm{a})=\mathrm{E}(\mathrm{e})=\mathrm{E}(\mathrm{r})=\mathrm{E}(\mathrm{t})=0 ; \mathrm{V}(\mathrm{r})=\mathrm{r}, \mathrm{V}(\mathrm{s})=$ $\mathrm{s}, \mathrm{V}(\mathrm{a})=\mathrm{G} ; \mathrm{V}(\mathrm{e})=\mathrm{R} ; \operatorname{cov}\left(\mathrm{a}, \mathrm{e}^{\prime}\right)=0$, and all other covariances were also assumed to be zero; and $\mathrm{V}(\mathrm{y})$ $=\mathbf{Z G Z}$ ' $+\mathbf{r}+\mathbf{s}+\mathbf{t}+\mathbf{R}$, where $\mathbf{G}$ is the direct product between the numerator relationship matrix (A) for animals and the matrix of genetic variance and co-variances, $\mathbf{G}=\mathbf{A} \otimes \mathbf{G} 0 ; \mathbf{R}$ is the direct product between an identity matrix of order of the number of observations and the matrix of error variances and covariances $(\mathbf{R}=\mathbf{I} \otimes \mathbf{R} 0)$.

The 3 cow fertility traits (NRRC, CTFS, and FSTC) were analyzed with a single trait analysis and with a bivariate analysis in which TD90M was included as correlated trait.

Genetic evaluation of animals, using genetic parameters obtained, was carried out using the different models explained above. Models were compared in terms of genetic trends (NRRC, CTFS, and FSTC) and cross-validation and predictability (NRRC). Estimated breeding values for NRRC, CTFS, and FSTC in first lactation from a total of 2,939 sires born between 1995 and 2002 with at least 50 daughters with records were selected. Their EBV, expressed as genetic standard deviations, were averaged by year of birth to estimate the genetic trend over time. Genetic trends were calculated for the 2 models for the 3 traits. Moreover, a separate bivariate analysis was performed including NRRC and NRRH as correlated traits. The 3 models for NRRC (single-trait and the 2 bivariate analyses, $\mathrm{NRRC}+\mathrm{TD} 90 \mathrm{M}$ and $\mathrm{NRRC}+\mathrm{NRRH}$ ) were compared with a cross-validation and predictability analysis. For the cross-validation analysis, the whole data set $\left(\mathbf{D A T A}_{\mathbf{W}}\right)$ was randomly divided in 2 subsets by herd, $\mathrm{DATA}_{1}$ and $\mathrm{DATA}_{2}$. Correlations of sire EBV between subset $\mathrm{DATA}_{1}$ and $\mathrm{DATA}_{2}$ were computed within each analysis for NRRC (single-trait, bivariate analysis of, NRRC together with milk production and bivariate analysis of NRRC together with NRRH). Rank correlations were calculated using EBV from sires with at least 50 daughter records in $\mathrm{DATA}_{\mathrm{W}}$. For the predictability analysis, a data set was extracted 4 yr prior (DATA p $_{\text {) }}$ to the extraction of the whole data set. The predictive ability of the 3 models was assessed by comparing the rank correlation between sire EBV from $\mathrm{DATA}_{W}$ and the older data set $\mathrm{DATA}_{\mathrm{p}}$. Again, only EBV from sires with at least 50 daughter records from the DATA $\mathrm{DW}_{W}$ were included in the analysis.

To estimate the genetic parameters, 15,000 records from randomly selected herds were used in each analysis. For breeding value estimation, the complete data set contained 1,147,770 animals and the number of sires included was 16,373. The DMU software package (Madsen and Jensen, 2006) was used for all analyses.

\section{RESULTS AND DISCUSSION}

\section{Genetic Parameters}

The estimates of heritability for NRRC from the univariate and bivariate analyses were $0.017 \pm 0.003$ and $0.020 \pm 0.004$, respectively. The corresponding results for CTFS were $0.070 \pm 0.001$ and $0.080 \pm 0.002$ and for FSTC were $0.049 \pm 0.003$ and $0.050 \pm 0.002$. Both models provided very similar heritability estimates (Table 1). These estimates of heritability are somewhat smaller than those estimates observed by Jamrozik et al. (2005) who reported 0.04, 0.099, and 0.07 for NRR, CTFS, and FSTC, respectively, using 16 traits for female reproductive performance in Canadian Holsteins. However, results from the current study are in line with recent literature estimates. In Danish Holsteins, Sun et al. (2009) reported estimates of $0.012,0.081$, and 0.030 for NRR, CTFS, and FSTC, respectively. In German Holsteins, Liu et al. (2008) estimated values of 0.015, 0.039, and 0.010 for NRR, CTFS, and FSTC, respectively. Hou et al. (2009) also reported a heritability value of 0.102 for CTFS when using a linear sire model in Danish Holsteins. In Australia, Haile-Mariam et al. (2008) found a heritability value of 0.01 for FSTC. Kadarmideen et al. (2003) estimated heritability values of 0.016 and 0.012 for CTFS and interval between first service and last service from a single trait analysis. The corresponding results from the bivariate analysis in which milk production was included in the model were 0.016 and 0.028 .

The genetic correlations between TD90M with NRRC, CTFS, and FSTC were $-0.13 \pm 0.02,0.29 \pm$ 0.05 , and $0.12 \pm 0.03$, respectively. This result shows that small undesirable genetic correlations exist between production and fertility traits. The correlation between CTFS and milk production was larger than the other correlations (TD90M and FSTC and TD90M and NRRC). These genetic correlations indicate that high-producing cows were bred later, took longer to conceive, and required more services per conception than low-producing cows. The possible explanation is that the dairy producer may inseminate high-yielding cows later than other cows in the herd. Moreover, a lack of heat symptoms in high-producing cows is another contributing factor. Even so, the magnitude of correlations between production and fertility traits such as NRRC and FSTC found in this study were low compared with other studies (Roxstrom et al., 2001). Berger et al. (1981) and Hansen et al. (1983) reported a substantial genetic antagonism between high yield and fertility traits in dairy cattle. Kadarmideen et al. (2003) reported a genetic correlation of 0.38 for interval between first and last service with milk production. They 
Table 1. Estimates of variance components for 56-d nonreturn rate in cows (NRRC) and heifers (NRRH), calving to first service (CTFS), and first service to conception (FSTC) from univariate and bivariate analyses with milk production (test-day milk yield closest to 90 DIM; TD90M)

\begin{tabular}{|c|c|c|c|c|c|c|c|c|}
\hline Source of variation ${ }^{1}$ & \multicolumn{2}{|c|}{$\mathrm{NRRC}^{2}$} & \multicolumn{2}{|c|}{ CTFS } & \multicolumn{2}{|c|}{ FSTC } & TD90M ${ }^{3}$ & $\mathrm{NRRH}^{2}$ \\
\hline RYSH & 9.623 & 5.798 & 28.784 & 28.674 & 6.49 & 6.681 & 25.12 & 4.3239 \\
\hline SSY & 0.344 & 0.274 & - & - & - & - & & 0.2780 \\
\hline Animal & 4.010 & 5.024 & 59.290 & 62.26 & 74.015 & 76.31000 & 581.117 & 3.1682 \\
\hline Residual & 217.715 & 213.839 & 746.460 & 744.05 & $1,412.85$ & $1,410.626$ & $1,559.510$ & 219.20 \\
\hline
\end{tabular}

${ }^{1} \mathrm{RYSH}=$ region-herd-year-season; TID = technician ID; SSY = service sire by year of insemination.

${ }^{2}$ Values are multiplied by 1,000 .

${ }^{3}$ Average of the 3 bivariate runs.

also reported a genetic correlation of 0.27 for interval between calving and conception with milk yield. Andersen-Ranberg et al. (2005) found a genetic correlation of 0.47 between CTFS and 305-d protein yield. Pryce et al. (2004) reported differences in fertility between a selection line of cows bred to bulls with the highest breeding values for fat plus protein yield available in the UK and a control line of cows bred to bulls with average breeding values. Their results showed that the selected line had poorer fertility with respect to calving interval, days to first heat, CTFS, days open, and conception rate at first service. Absence of an appreciable correlation between milk production and female fertility traits in Canadian Holsteins compared with other countries may be the result of Canada's longstanding balanced breeding approach that includes selection for high production combined with superior conformation to support such production levels. However, to warrant this assumption, further studies should be carried out to evaluate the relationship between fertility traits and conformation traits in Canadian dairy breeds.

The genetic correlation between NRRH and NRRC was 0.57 , which is slightly smaller than the value of 0.6 reported by Jamrozik et al. (2005). Andersen-Ranberg et al. (2005) reported a genetic correlation of 0.54 in Norwegian dairy cattle between NRRH and NRRC in first lactation. Moreover, a genetic correlation of 0.55 was found by Oltenacu et al. (1991) between first-service pregnancy in heifers and first-lactation cows in Swedish dairy cattle. De Jong (1997), however, found a genetic correlation of 0.12 between NRRH and NRRC. Usually, if producers observe any fertility problem in heifers, they are less tempted to breed the animal in the future, causing some sort of sequential selection. Therefore, adding heifer records in the model as a correlated trait improves the accuracy of evaluation and reduces the effect of culling or selective treatment, which may bias fertility traits as shown by Kadarmideen et al. (2003).

\section{Genetic Trends}

The resulting genetic trends for NRRC, CTFS, and FSTC from a single trait and from a bivariate analysis including TD90M as a correlated trait are shown in Figures 1, 2, and 3, respectively. The genetic trend, expressed as genetic standard deviations for NRRC from a bivariate analysis in which $\mathrm{NRRH}$ as a correlated trait is also presented is in Figure 4. Figure 1 shows the genetic trends for NRRC. Trends were more or less flat. The genetic trend from univariate analysis was slightly higher in the last $2 \mathrm{yr}$ than in the preceding years. The inclusion of milk production as a correlated trait in the model for the analysis of NRRC had a small influence on the genetic trend. Figure 2 shows that the genetic trend for CTFS in the univariate analysis was irregular until the 1997 birth year and then increased over time. However, the inclusion of milk yield in the model had a clear effect, increasing the trend by 0.07 genetic standard deviations per year. The genetic trend for FSTC is shown in Figure 3. Similar to CTFS, the inclusion of milk yield in the model increased the genetic trend for FSTC. However, the increase was smaller (0.02 genetic standard deviations per year). Figure 4 shows that including NRRH as a correlated trait had a similar small effect on genetic trend for NRRC as including TD90M as a correlated trait. However, further studies should be carried out to estimate the precision of the 2 models. An unfavorable genetic trend was also reported for female fertility traits by Liu et al. (2008). The authors reported a decrease of $2.7 \%$ of nonreturn rate between 1994 to 2005 in German Holstein bulls.

\section{EBV Correlations Using the Full Data Set}

Calculating the correlation between the EBV for NRRC obtained from the 3 models showed that the correlations between EBV from the single trait model 


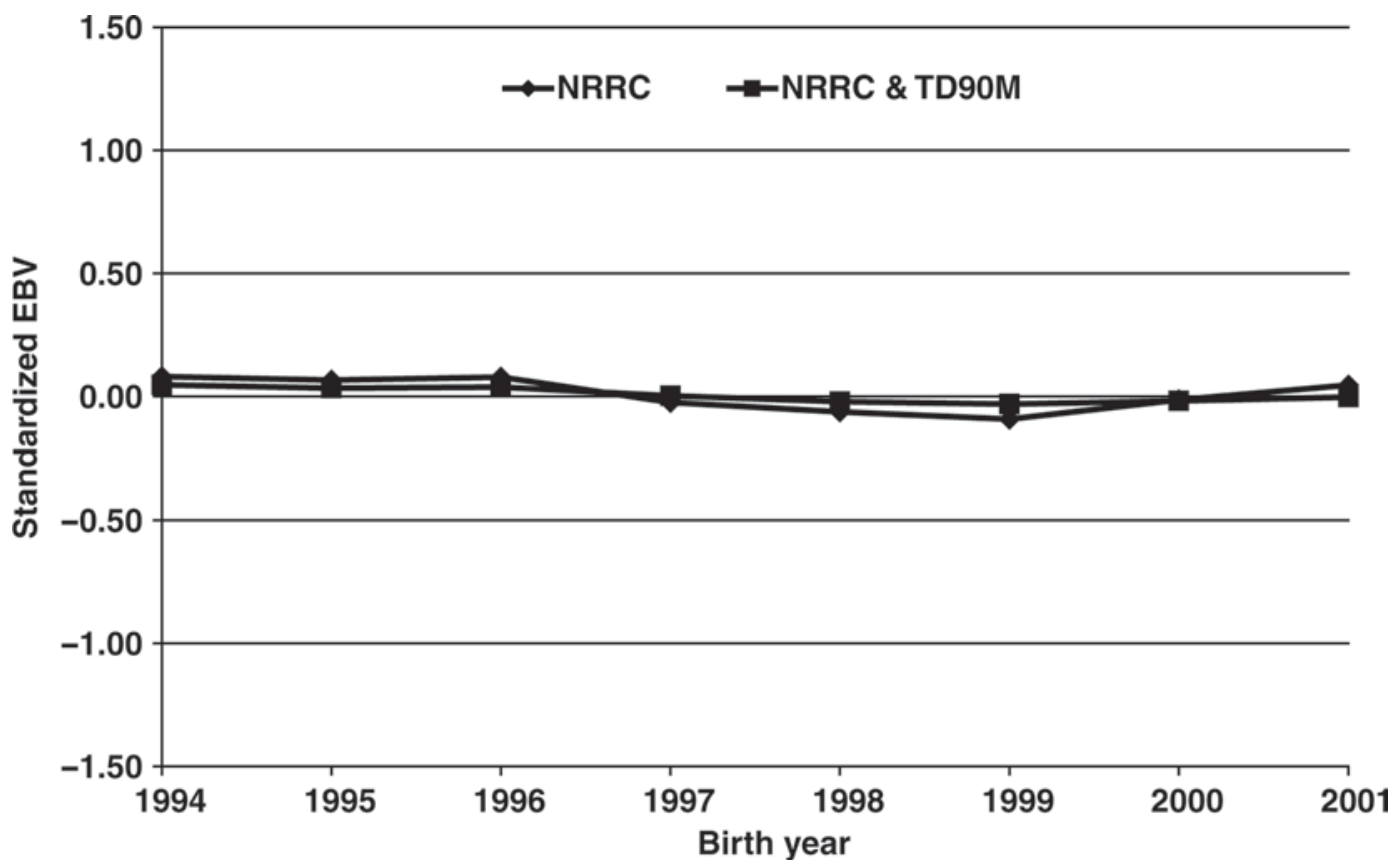

Figure 1. Genetic trend expressed as genetic standard deviation unit for 56-d nonreturn rate (NRR) from NRR and NRRC (nonreturn rate in cows) + TD90M (test-day milk yield closest to 90 DIM) analyses for first-parity cows.

and the 2 multitrait models were 0.90 and 0.91 when using NRRH and TD90M as correlated traits, respectively. Including TD90M or NRRH as a correlated trait resulted in similar EBV for the selected bulls (correla- tion was 0.98$)$. Thus, in contrast with the genetic trend comparison, including NRRH or TD90M as a correlated trait had a clear effect on EBV and it was very similar between the 2 bivariate analyses.

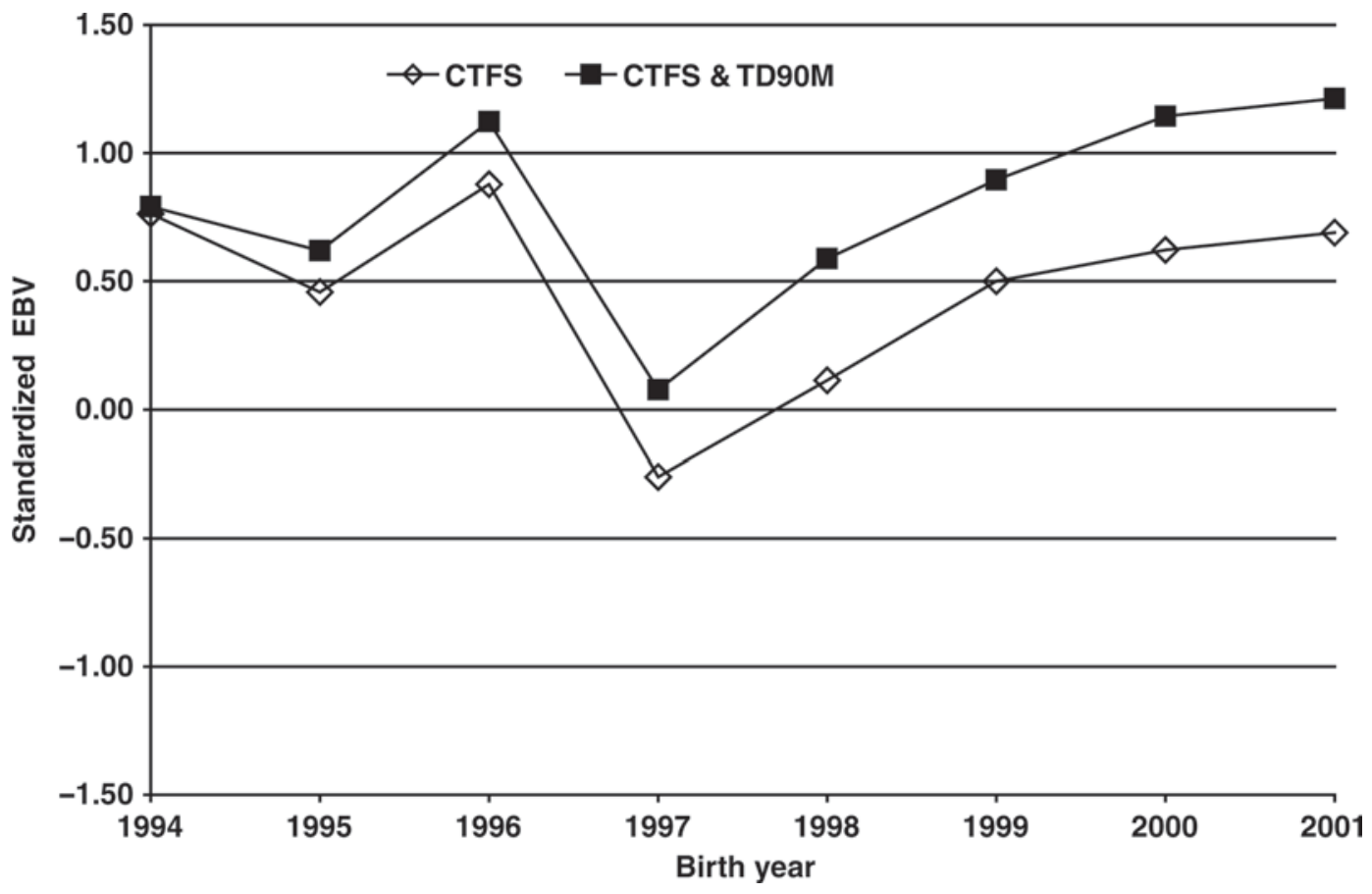

Figure 2. Genetic trend expressed as genetic standard deviation unit for calving to first service (CTFS) from CTFS and CTFS + TD90M (test-day milk yield closest to 90 DIM) analyses for first-parity cows. 


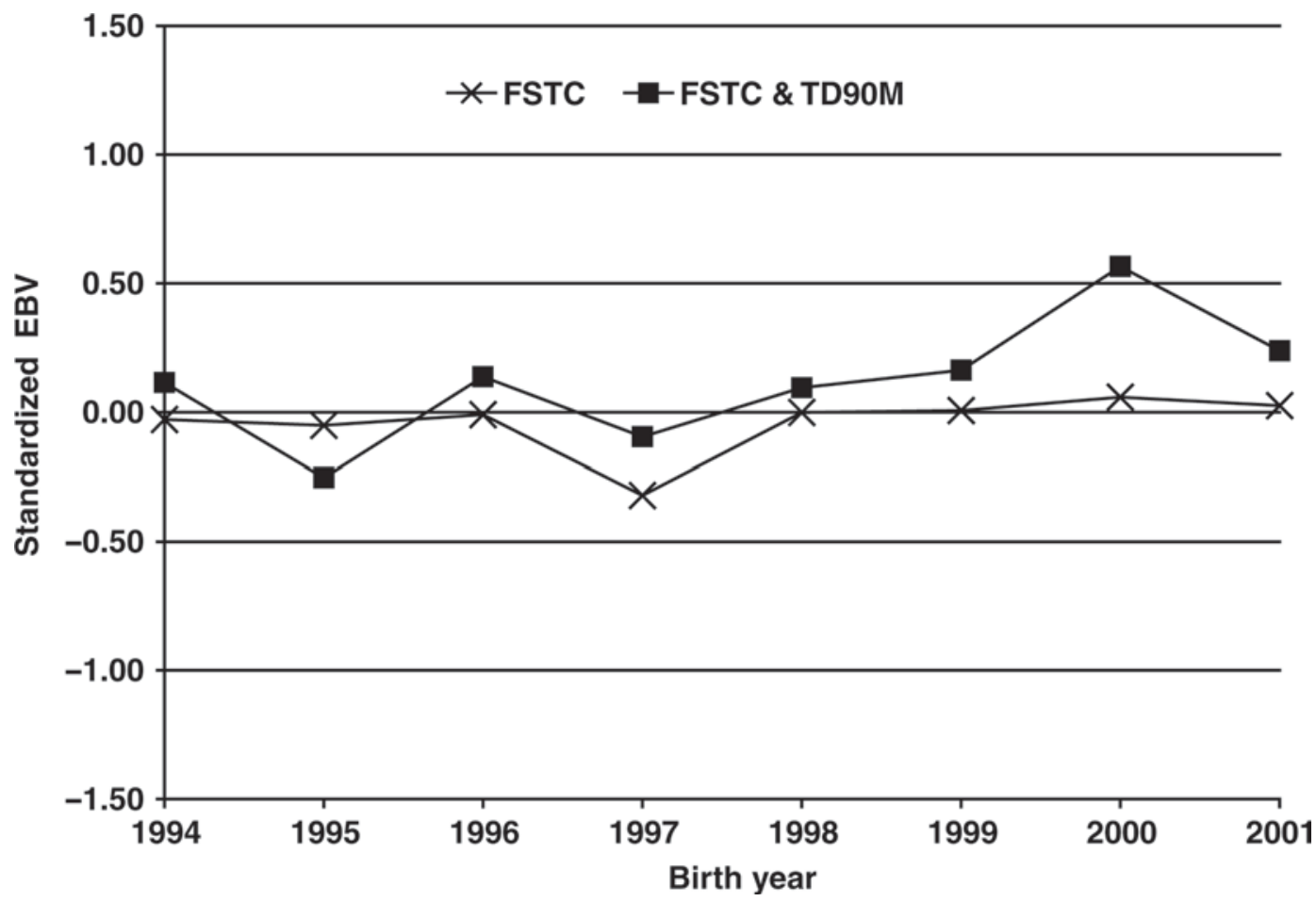

Figure 3. Genetic trend expressed as genetic standard deviation unit for first service to conception (FSTC) from FSTC and FSTC + TD90M (test-day milk yield closest to 90 DIM) analyses for first-parity cows.

\section{Cross-Validation and Predictability}

Model stability in terms of sire EBV was assessed as the correlation between EBV from subsets DATA 1 and $\mathrm{DATA}_{2}$. The rank correlations were 0.69 for single trait analysis, 0.74 for the bivariate analysis with TD90M, and 0.73 for the bivariate analysis with NRRH. This result shows that the bivariate analyses gave more consistent bull EBV than did the single trait analysis. The predictive ability of the 3 models was assessed by a comparison on the rank correlation between sire EBV from whole data set DATA $w$ and data set DATA . The rank correlation between the 2 data set for the 3 models were $0.73,0.76$, and 0.78 for NRRC, NRRC+NRRH, and NRRC+TD90M, respectively, showing again that the bivariate analyses had better predictive ability than the single trait analysis. Additionally, there was no major difference between the 2 bivariate models, even if there was a tendency of better predictability when TD90M was included instead of NRRH (0.78 vs. $0.76)$. Within each subset of data $\left(\mathrm{DATA}_{1}\right.$ and $\left.\mathrm{DATA}_{2}\right)$, EBV correlations between single and bivariate models were calculated. For $\mathrm{DATA}_{1}$ the rank correlations were 0.91 and 0.93 for NRRC+NRRH and NRRC+TD90M, respectively. The corresponding figures for $\mathrm{DATA}_{2}$ were 0.89 and 0.090 .
Kadarmideen et al. (2003) strongly recommended including milk production as a correlated trait in female fertility evaluations, because single trait fertility analyses may be biased if they do not include the milk yield data on which selection decisions were based. However, Kadarmideen et al. (2003) did not study heifer fertility traits (such as NRRH) to observe if similar results were obtained. Additionally, Miglior et al. (2005) reported a considerable shift in the global trend of selection from production to functional traits such as fertility and health-related traits. For instance, in Canada, CDN (2009) reported that $30 \%$ of culling decisions are based on reproduction traits followed by conformation (20\%), SCC (18\%), disease (12\%), and production (9\%) traits. Therefore, including NRRH as a correlated trait in cow female fertility evaluation seems the right approach to decrease the effect of culling bias practiced on fertility traits.

\section{CONCLUSIONS}

In this study, minimal differences in the heritability of female fertility traits were obtained between univariate and bivariate analyses in which TD90M was included as a correlated trait. An unfavorable genetic correlation between milk production and fertility traits was 


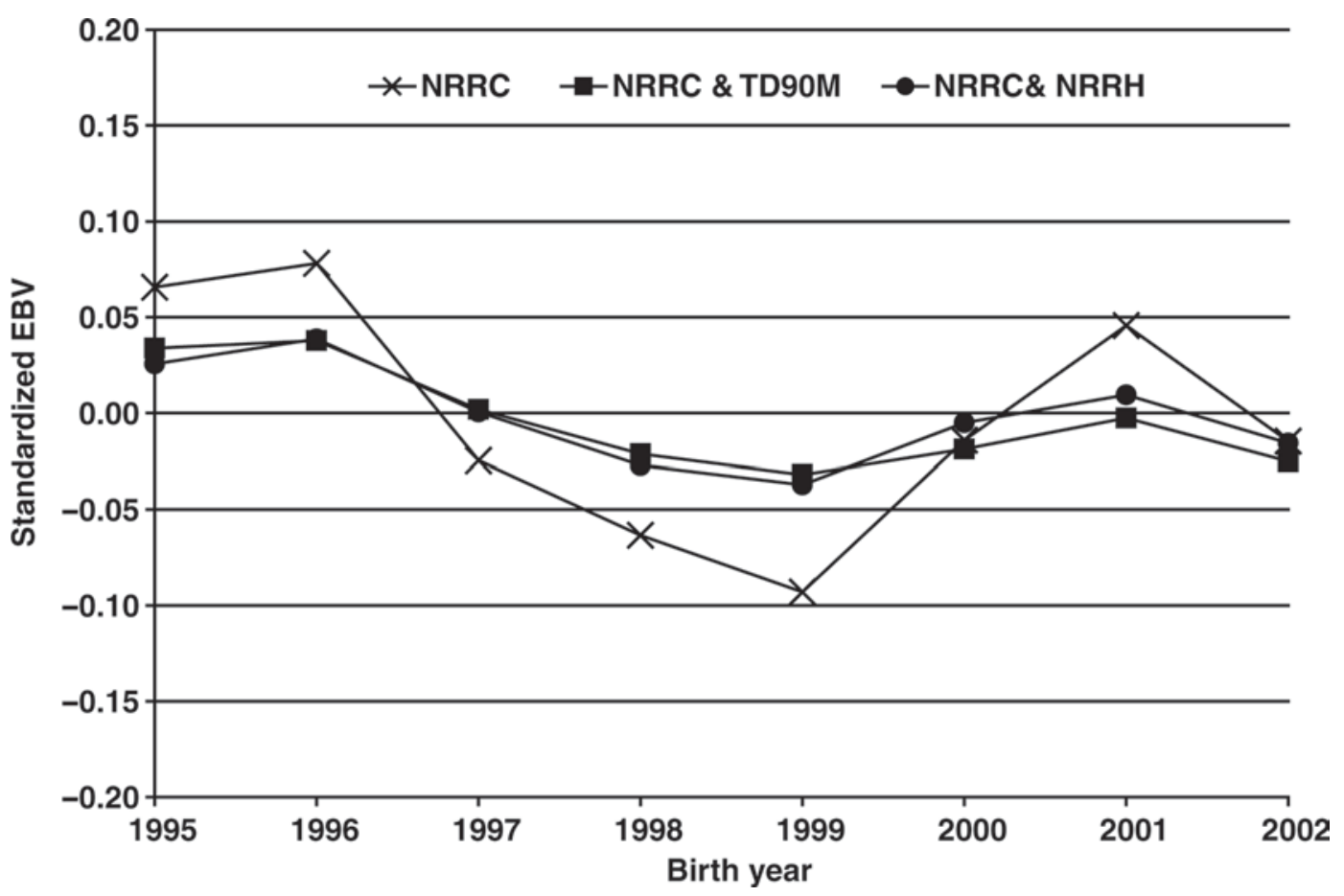

Figure 4. Genetic trend expressed as genetic standard deviation unit for 56-d nonreturn rate in cows (NRRC), with heifer data (NRRC and NRRH; NRR in heifers) and with milk (NRRC + TD90M; test-day milk yield closest to 90 DIM) analyses for first-parity cows.

observed, but was of smaller magnitude than previously found for NRRC and FSTC. Genetic trends for female fertility traits found in this study were smaller than results reported elsewhere. Adding milk production or heifer nonreturn rate as a correlated trait with NRRC had little effect on the genetic trend of NRRC and had a clear effect on sire EBV. Results from bivariate analyses of NRRC were more consistent and had better predictability than did the single trait analysis. Including TD90M or NRRH in genetic analysis of cow fertility may help to account for selection and avoid bias on the estimated genetic parameters and might increase the accuracy of selection. However, further studies should be carried out to verify if there is a significant increase in the accuracy of EBV.

\section{REFERENCES}

Andersen-Ranberg, I. M., G. Klemetsdal, B. Heringstad, and T. Steine. 2005. Heritabilities, genetic correlations, and genetic change for female fertility and protein yield in Norwegian dairy cattle. J. Dairy Sci. 88:348-355.

Berger, P. J., R. D. Shanks, A. E. Freeman, and R. C. Laben. 1981. Genetic aspects of milk yield and reproductive performance. J. Dairy Sci. 64:114-122.

Castillo-Juarez, H., P. A. Oltenacu, R. W. Blake, C. E. McCulloch, and E. G. Cienfuegos-Rivas. 2000. Effect of herd environment on the genetic and phenotypic relationships among milk yield, conception rate, and somatic cell score in Holstein cattle. J. Dairy Sci. $83: 807-814$.
CDN. 2009. Canadian Dairy Network: Trends in Disposal Reasons (http://www.cdn.ca/document.php?id=165). Accessed in April 2010.

De Jong, G. 1997. Index for daughters' fertility in the Netherlands. Interbull Bull. 18:102-105.

Dematawewa, C. M. B., and P. J. Berger. 1998. Genetic and phenotypic parameters for 305-day yield, fertility, and survival in Holstein. J. Dairy Sci. 81:2700-2709.

Gonzalez-Recio, O., R. Alenda, Y. M. Chang, K. Weigel, and D. Gianola. 2006. Selection for female fertility using censored fertility traits and investigation of the relationship with milk production. J. Dairy Sci. 89:4438-4444.

Gonzalez-Recio, O., M. A. Perez-Cabal, and R. Alenda. 2004. Economic value of female fertility and its relationship with profit in Spanish dairy cattle. J. Dairy Sci. 87:3053-3061.

Grosshans, T., Z. Z. Xu, L. J. Burton, D. L. Johnson, and K. L. MacMillan. 1997. Performance and genetic parameters for fertility of seasonal dairy cows in New Zealand. Livest. Prod. Sci. 51:4151 .

Haile-Mariam, M., and M. J. Carrick., and M. EGoddard, . 2008. Genotype by environment interaction for fertility, survival, and milk production traits in Australian dairy cattle. J. Dairy Sci. 91:4840-4853.

Hansen, L. B., A. E. Freeman, and P. J. Berger. 1983. Yield and fertility relationships in dairy cattle. J. Dairy Sci. 66:293-305.

Hou, Y., P. Madsen, R. Labouriau, Y. Zhang, M. S. Lund, and G. Su. 2009. Genetic analysis of days from calving to first insemination and days open in Danish Holsteins using different models and censoring scenarios. J. Dairy Sci. 92:1229-1239.

Jamrozik, J., J. Fatehi, G. J. Kistemaker, and L. R. Schaeffer. 2005. Estimates of genetic parameters for Canadian Holstein female reproduction traits. J. Dairy Sci. 88:2199-2208.

Kadarmideen, H. N., R. Thompson, M. P. Coffey, and M. A. Kossaibati. 2003. Genetic parameters and evaluations from single and multiple trait analysis of dairy cow fertility and milk production. Livest. Prod. Sci. 81:183-195. 
Kadarmideen, H. N., R. Thompson, and G. Simm. 2000. Linear and threshold model genetic parameters for disease, fertility and milk production in dairy cattle. Anim. Sci. 71:411-419.

Liu, Z., J. Jaitner, F. Reinhard, E. Pasman, S. Rensing, and R. Reents. 2008. Genetic evaluation of fertility traits of dairy cattle using a multiple-trait animal model . J. Dairy Sci. 91:4333-4343.

Madsen, P., and J. Jensen, 2006. DMU, a Package for Analyzing Multivariate Mixed Models. Version 6, release 4.6. Faculty of Agricultural Sciences (DJF), Department of Genetics and Biotechnology, Research Centre Foulum, Tjele, Denmark.

Melendez, P., and P. Pinedo. 2007. The association between reproductive performance and milk yield in Chilean Holstein cattle. J. Dairy Sci. 90:184-192.

Miglior, F., B. L. Muir, and B. J. Van Doormaal. 2005. Selection indices in Holstein cattle of various countries. J. Dairy Sci. $88: 1255-1263$

Oltenacu, P. A., A. Frick, and B. Lindhé. 1991. Relationship of fertility to milk yield in Swedish cattle. J. Dairy Sci. 74:264-268.

Pollak, E. J., and R. L. Quaas. 1981. Monte Carlo study of genetic evaluations using sequentially selected records. J. Anim. Sci. $52: 257-264$.

Pryce, J. E., M. D. Royal, P. C. Garnsworthy, and I. L. Mao. 2004. Fertility in the high-producing dairy cow. Livest. Prod. Sci. $86: 125-135$.

Roxstrom, A., E. Strandberg, B. Berglund, U. Emanuelson, and J. Philipsson. 2001. Genetic and environmental correlations among female fertility traits and milk production in different parities of Swedish red and white dairy cattle. Acta Agric. Scand. 51:7-14.
Sewalem, A., F. Miglior, G. J. Kistemaker, and B. J. Van Doormaal. 2006. Analysis of the relationship between somatic cell score and functional longevity in Canadian dairy cattle. J. Dairy Sci. 89:3609-3614.

Sewalem, A., F. Miglior, G. J. Kistemaker, and B. J. Van Doormaal 2008. Analysis of the relationship between fertility traits and longevity in Canadian dairy breeds using a weibull proportional hazards model. J. Dairy Sci. 91:1660-1668.

Simianer, H., H. Solbu, and L. R. Schaeffer. 1991. Estimated genetic correlations between disease and yield traits in dairy cattle. J. Dairy Sci. 74:4358-4365.

Sun, C., P. Madsen, U. S. Nielsen, Y. Zhang, M. S. Lund, and G. Su. 2009. Comparison between a sire model and an animal model for genetic evaluation of fertility traits in Danish Holstein population. J. Dairy Sci. 92:4063-4071.

Van Doormaal, B. J., G. J. Kistemaker, and F. Miglior. 2007 Implementation of reproductive performance genetic evaluations in Canada. Interbull Bull. 37:129-133.

Veerkamp, R. F., E. P. C. Koenen, and G. De Jong. 2001. Genetic correlations among body condition score, yield, and fertility in first-parity cows estimated by random regression models. J. Dairy Sci. 84:2327-2335

Wall, E., S. Brotherstone, J. A. Woolliams, G. Banos, and M. P. Coffey. 2003. Genetic evaluation of fertility using direct and correlated traits. J. Dairy Sci. 86:4093-4102.

Walter, I. P., and I. L. Mao. 1985. Multiple and single traits analyses for estimating genetic parameters in simulated populations under selection. J. Dairy Sci. 68:91-98. 